\title{
Perceptions of Actors on the Community-Based Maternal and Neonatal Health Services Project at the Kolda and Sedhiou Regions
}

\author{
Alioune Badara Tall1, Jean Augustin Diegane Tine², Awa Gaye', Abdoul Aziz Ndiaye1, \\ Adama Faye ${ }^{2}$, Anta Tal-Dia² \\ ${ }^{1}$ UFR SDD/Bambey University, Bambey, Senegal \\ ${ }^{2}$ FMPOS/ISED/UCAD, Dakar, Senegal \\ Email: tallalioune@yahoo.fr
}

How to cite this paper: Tall, A.B., Tine, J.A.D., Gaye, A., Ndiaye, A.A., Faye, A. and Tal-Dia, A. (2018) Perceptions of Actors on the Community-Based Maternal and Neonatal Health Services Project at the Kolda and Sedhiou Regions. Health, 10, 1749-1763. https://doi.org/10.4236/health.2018.1012132

Received: October 23, 2018

Accepted: December 18, 2018

Published: December 21, 2018

Copyright (c) 2018 by authors and Scientific Research Publishing Inc. This work is licensed under the Creative Commons Attribution International License (CC BY 4.0).

http://creativecommons.org/licenses/by/4.0/

\begin{abstract}
Introduction: The health of mothers and children remains a major concern in developing countries. Infant and maternal mortality rates, although declining, are still high. Access to health services is a major obstacle to reducing maternal and infant mortality. To support the Ministry of Health and Social Action in the implementation of its Strategic Plan for Reproductive Health (2012-2015), the NGO Micronutriment Initiative has developed a project based on community-based maternal and neonatal health services (CBMNHS) in the Kolda region. The general objective of this study is to collect the perceptions of the actors on the Community-Based Maternal and Neonatal Health Services project in the Kolda and Sedhiou regions. Method: This was a qualitative study consisting of an evaluation of the activities carried out within the framework of the CBMNHS project at the level of the intervention zone. The study focused on support groups, community actors, post nurses and implementers of the intervention. Sampling was comprehensive for community actors and nurse heads. Focus groups and in-depth individual interviews were used to assess the perceptions of women and support groups, as well as to better understand the dynamics of the intervention. The content analysis was performed to exploit the qualitative data. Results: All local and national health authorities interviewed are unanimous about the relevance of the project. The project's strategies are essentially community-oriented. Thus, a large number of committees have been set up. A total of 1258 support groups were set up during the project, distributed as follows: 260 grandmother groups (Grandmothers Strategy); 266 groups of pregnant women (Pregnant Women's Solidarity Circles); 248 Care Group; 468 community watch and alert circles and 16 Future Fathers' Groups (Future Fathers' Solidarity Circles). These committees aimed to involve women of reproductive age,
\end{abstract}


mothers, mothers-in-law and fathers. More than $70 \%$ of women surveyed agree that support groups have improved their knowledge of maternal health, nutrition, and children's health. Groups also improved their attendance at health facilities, which is a major asset of the project. Conclusion: The analysis of the perception of the different actors of the CBMNHS project shows that the project is well conducted in the area of intervention that is the region of Kolda. However, the central question of the success of sustainability is the existence of a withdrawal plan. Indeed, this plan must be studied from the very beginning and must be adapted to the local context. As a result, support groups are urged to become more involved in reproductive health activities, especially those related to the exclusive breastfeeding, and to continue to provide all forms of support (financial and moral) to women of reproductive age for reproductive health carrying out reproductive health activities for better access to services.

\section{Keywords}

Perception, Maternal and Neonatal Health, Community, Kolda

\section{Introduction}

Maternal, perinatal and neonatal mortality is a major public health problem. According to WHO, most of these deaths (99\%) occur in developing countries, and more than half in sub-Saharan Africa [1]. In Senegal, the maternal mortality rate is 392 deaths per 100,000 live births [2]. The causes of maternal mortality are mainly postpartum haemorrhage, arterial hypertension and its complications, dystocia, infections and abortions [3]. The neonatal mortality rate in Senegal is 29 deaths per 1000 live births. The causes are infections (especially neonatal tetanus), prematurity, asphyxia and congenital malformations [2]. About $80 \%$ of maternal and neonatal deaths could be prevented if key interventions were implemented as part of a continuum of care linking families and communities to health systems.

To accelerate progress in reproductive health, the Ministry of Health and Social Action of Senegal (MHSA) has developed its Strategic Plan for Reproductive Health (2012-2015), whose objectives focus on: among other things, strengthening the community component in interventions to improve access to maternal and newborn health. This has led the Micronutrient Initiative (MI) to work in collaboration with the MHSA to operationalize the implementation of maternal and newborn health interventions at the community level in Senegal.

Before the implementation of the service package in the Kolda region, a baseline study was conducted in January 2014 on key maternal and neonatal health indicators in the Kolda region (intervention) and the Sedhiou health district (comparison). This analysis was conducted in health centers and at community level and was completed in six weeks.

The general objective of this study is to collect the perceptions of the actors on 
the Community-Based Maternal and Neonatal Health Services (CBMNHSS) project in the Kolda and Sedhiou regions.

\section{Material and Methods}

\subsection{Quotation}

The qualitative method makes it possible to apprehend the perceptions of the populations on these problems.

The research strategy that is used is a contrasting case study [4]. Our case consists of an intervention carried out in the three health districts of the Kolda region with a control zone which is Sedhiou District.

This qualitative study consists of an evaluation of the activities carried out as part of the CBMNHS project at the intervention zone level. The studies are based on the analysis of stakeholders' experiences and perceptions of the role of support groups on maternal and child health and nutrition; approach that assessed the intensity of project interventions. Focus groups and in-depth individual interviews were conducted among the main actors involved in this intervention.

We were interested in the activities carried out to see the knowledge of these interventions at the level of the health establishments by the actors and their adhesion allowing thus to appreciate the durability of the project. These activities include: strengthening the supply and quality of services at the community level, including training of community health workers, equipment of health huts, expansion of the service package (management of haemorrhages postpartum, home care for newborns); organization of community health workers into associations around health posts, then into networks in the health district; development of management guidelines, CCC/IEC packages, training manual and community health system information for the CBMNHS project; and strengthening of the reference system.

We have tried to understand whether the CBMNHS project is perceived as having the expected benefits in terms of improved access to prenatal care and access to knowledge to reduce mortality.

\subsection{Study Population}

It concerned:

- All the women of reproductive age of the Kolda region and the health district of Sédhiou;

- Members of regional health teams;

- The Director of the Reproductive Health and Child Survival Directorate (RHCSD);

- The leaders of ChildFund;

- MI managers.

\subsection{Sampling}

We used reasoned sampling. This choice was based on the fact that we were not 
looking for completeness or statistical representativeness, but we made sure to make a choice that would allow to cross-check and reach all the strategic groups related to the implementation of the Neonatal Maternal Health Project. and at the community level.

1st degree: The CBMNHS project was held in Kolda. The region of Sedhiou with the same maternal and neonatal health indicators as Kolda served as a control zone. For Kolda all the districts were invested (Kolda, Vélingara, Medina Yoro Foula). Sedhiou being the control zone, only one of its districts was investigated, in this case that of Sedhiou. In addition, we also looked at stakeholders at regional (Medical Region) and national (RHCSD, ChildFund and MI) levels.

2nd degree: In each district, two positions have been chosen, one urban and one rural. We also took into account the presence of implementing partners (World Vision, ChildFund). In each health post, the participants were also chosen according to a reasoned choice based on the methodological needs of the study. The Vélingara area being specific because the two project implementing NGOs are involved, three health posts were chosen: one urban, and two rural including the health post of Medina Gounass which is the only one. Health post of Vélingara where ChildFund intervenes. Which makes us eight health post visited.

In the 3rd degree: for the rural posts, in addition to the interviews of the post, a health box is chosen in a reasoned way to be able to investigate the communities. The participants were initially approached through the community health workers surveyed, who know the women included in the survey, and only afterwards by the qualitative researcher when the person confirms his/her interest in participating in the socio-economic survey anthropological. Only participants who agreed to participate in the study were interviewed.

Interview guides for interviews and focus groups were developed.

\subsection{Data collection Method}

This evaluation was based primarily on a desk review and individual and group interviews to gather information on project implementation as well as on the experience of pregnancy targets after delivery.

\subsubsection{The Documentary Review}

It allowed to review the various documents of the project:

- Working documents (planning, administrative notes...)

- Minutes of meetings

- Activity reports

\subsubsection{Semi Structured Interviews}

These interviews concerned all the actors who intervened since the elaboration until the implementation. At the national level, the Director of the RHCSD, the coordinator of the Community Health Unit, the Project Manager at the MI level and the Project Coordinator at ChildFund. At the level of the medical regions, 
the Regional Chief Medical Officers and their reproductive health coordinators allowed us to document the implementation of the project. In the districts of Kolda, Medina Yoro Foula, Vélingara and Sédhiou, District Chief Medical Officer, HR Coordinator and midwife were interviewed.

\subsubsection{Focus Groups}

During this survey, we conducted ten (10) focus-groups, including 08 with mothers of children aged 0 to 11 months and 2 with members of community watch and alert circles (CVAC in French) to discuss the issue MI interventions in the areas visited and neonatal and infant maternal health. Open-ended questions allowed to obtain more detailed explanations on the report to the interventions of the Neonatal and Infant Maternal Health Project, the successes noted but also to identify obstacles in its implementation.

Focus groups brought together approximately 10 people each and reached approximately 100 people. The participants in the focus groups were chosen from a reasoned choice taking into account their knowledge of the interventions.

These focus groups took into account aspects of homogeneity. Indeed, to respect the principle of this tool, the men were not put in the same groups as the women to limit the possible factors of inhibition during the discussions.

\subsection{Seizure and Cleaning Plan}

All interviews and focus groups are recorded using a dictaphone. The interviews are transcribed by the investigators. Transcripts of interviews are coded by the coordinating anthropologist of the survey. A quality control is carried out based on the use of a sample of transcripts that is controlled (listening, rereading transcripts) by the manager. The transcripts are then assigned in a qualitative analysis software.

\subsection{Data Analysis Plan}

The data collected in this study are analyzed with the Nvivo software. This software facilitates the classification of data and releases the results. It facilitates the consideration of stakeholders through classification options. Thus, separate files gathering individual interviews, group interviews, documents collected are considered in order to facilitate targeted queries on the data collected.

A content analysis is performed. The documentary analysis serves as a complement to these data from a triangulation perspective. It covers planning documents and activity reports of interventions, action plans of health districts as well as national policy documents.

\section{Results}

\section{1) Analysis of the documentary review}

This analysis makes it possible to assess the relevance of the project and is interested in its raison d'être, its conformity with expressed needs and objectives.

The expected results of the project were: 
- Maternal support groups are trained and provide support to women in the search for quality maternal and newborn health care.

- Skilled health providers provide quality maternal and newborn health care at the community level and in the facilities.

- Community actors provide quality maternal and neonatal health services.

The health of the mother and child due to morbidity and mortality is a major public health problem in the Kolda region where these indicators are very high [2] [5]; hence the relevance of setting up a set of activities related to prenatal consultation (ANC), childbirth and care at the neonatal level. The project was developed after rigorous documentation but above all a situational analysis conducted in Kolda. Thus the specific needs of the Kolda region have been identified. This analysis made it possible to capitalize all the interventions developed in Kolda. The choice of ChildFund is also a relevant argument because of its community experience in the Kolda region. All local and national health authorities interviewed are unanimous about the relevance of the project.

The project's strategies are essentially community-oriented. Thus, a large number of committees have been set up. A total of 1258 support groups were set up during the project, distributed as follows: 260 grandmother groups (Grandmothers Strategy); 266 groups of pregnant women (Pregnant Women's Solidarity Circles); 248 Care Group; 468 CVAC and 16 Future Fathers' Groups (Future Fathers' Solidarity Circles). These committees aimed to involve women of reproductive age, mothers, mothers-in-law and fathers. This approach is relevant as most of the partners were at the level of the structures through capacity building and equipment while several studies have shown that the problems are at the community level.

In addition to the usual communication activities of interpersonal communication (IPC) and integrated home visiting (VADI in French), the project has developed innovative strategies. During the project period, 71715 IEC/BCC activities on maternal and neonatal health $(\mathrm{MNH})$ were conducted: 41,300 talks and one-on-one interviews, $2046 \mathrm{VADIs}$ and 10,147 innovative strategies. A total of 243,819 people ( $74 \%$ women) were affected through these activities.

The capacity building of communities to support the health of maternal and neonatal services was done through the creation of Village Savings and Loan Associations (AVEC in French): 193 AVEC were formed. The recruitment of 09 facilitators to support AVEC has made it possible to strengthen the monitoring and support of these structures. However, if we know the low savings capacity in the rural world we can ask questions about the relevance of the creation of these associations. Perhaps it was more relevant to articulate this intervention on existing organizations and see how to get people to benefit from the credits.

As part of the capacity building of districts and health posts in community-based health maternal and neonatal (HMN), several strategies have been developed. Reinforcement of existing strategies through the organization of advanced integrated strategies (SAI in French) that reach out to remote popula- 
tions with difficult access to structures. Thus 2918 SAI were carried out from April 2014 to December 2015, i.e. an average SAI per box every 2 months.

The involvement of the administrative authorities and local elected representatives in monitoring the activities of the HMN Community project is to be welcomed. This involvement of local elected officials is all the more relevant as it has helped to set up a system of reference and counter-reference to the different levels of the local health system through the strategy of waiting houses for pregnant women (MAFE in French). These MAFEs welcome pregnant women who have come to give birth in the structures and who have no close relatives to welcome them. In Medina Yoro Foulah (MYF) and Vélingara, it is the local elected officials who made the premises available. The establishment of MAFEs has been particularly appreciated by the health authorities. However, some people are wondering about its location outside health facilities as a claimant attests "people will not accept that their wives live in houses in town". This may explain the low volume of activity of the MAFE: A total of 08 pregnant women were admitted, including 3 in the MAFE Kolda and 05 in the district of Vélingara despite the promotional activities of the MAFE organized in the 3 districts type contractualisation with community radios (6), the production of spots (375) and radio broadcasts (34), the organization of social mobilisations (2). The fact that MAFE Kolda is installed at the health center level is an interesting experience.

The project has promoted the development of HMN services at the community level. This was done by putting in place the boxes, equipment boxes and training of matrons and community health actors. However, the project faced supervisory difficulties due to the inadequacy of midwives. Human resource support for health posts and health centers through the recruitment of midwives was relevant.

Financial resources were directly managed by ChildFund. This could create delays for disbursement according to some interviewees. Others pointed to the late availability of reports because ChildFund did not have a contractual obligation with the MHSA. Increasingly contracting with medical programs or regions is the new approach. This strategy aims to strengthen the medical region authority.

2) Intensity of the intervention

3) Health facility evaluation in relation to the sustainability of the project

\section{Discussion}

The discussion of the results will be articulated author of two points

- Analysis of the intensity of the intervention

- Sustainability analysis

\subsection{Analysis of the Intensity of the Intervention}

The analysis of the intensity of several interventions may be part of a temporo-spatial analysis. It consists in identifying for each place the period of imple- 
mentation of each intervention. This approach is very relevant to long-term, large-scale projects where interventions are implemented at intervals of time. This is not the case for the CBMNHS project where an intervention package is set up almost at the same time in a region. In these cases it is better to appreciate the intensity at the individual level. This is the number of interventions that the person has directly benefited [6].

The evaluation of the intensity of the intervention was initially evaluated on the role of maternal support groups on maternal health, nutrition, children's health, advice received and attendance at health facilities. If we consider the items totally agree and agree, we note that the women interviewed are $79.6 \%$ in Kolda, 76.5\% in MYF, 87.9\% in Vélingara and 34.3\% in Sedhiou on the contribution of support groups on the health of the mother. For nutrition these proportions are respectively at $73.2 \%, 68.6 \%, 82.3 \%$ and $38.4 \%$. These results show that women have a good appreciation of nutritional support groups (Table 1).

The positive assessment of maternal support groups on children's health shows that $74.5 \%$ of women surveyed in Kolda, $73.6 \%$ in MYF, $84 \%$ in Vélingara and $45.2 \%$ in Sédhiou agreed. The same is true for the advice received during the meetings, the results show $77.3 \%$ in Kolda, $72.2 \%$ in MYF and $79.6 \%$ in Vélingara and only $38.1 \%$ in Sedhiou (Table 2 ).

The main objective of this project is to improve the attendance of health services by women. The highest proportion was noted in Velingara with $79.8 \%$, followed by Kolda $72.2 \%$ and $71 \%$ at MYF (Table 3 ).

The indirect analysis of intensity through the perception of women about the

Table 1. Evaluation of the intensity of the intervention on the role of maternal support groups on maternal health and nutrition according to the health districts.

\begin{tabular}{cccccccccc}
\hline & \multicolumn{2}{c}{ KOLDA } & \multicolumn{2}{c}{ MYF } & \multicolumn{2}{c}{ VELINGARA } & \multicolumn{2}{c}{ SEDHIOU } \\
\cline { 2 - 9 } & $\%$ & $\mathbf{N}$ & $\%$ & $\mathbf{N}$ & $\%$ & $\mathbf{N}$ & $\%$ & N \\
\hline $\begin{array}{c}\text { I learned more about maternal health } \\
\text { through the maternal support group }\end{array}$ & & & & & & & & \\
Totally agree & 32.2 & 59 & 6.2 & 226 & 39.8 & 108 & 3.6 & 140 \\
Okay & 47.4 & 59 & 70.3 & 226 & 48.1 & 108 & 30.7 & 140 \\
Somewhat agree & 15.2 & 59 & 1.3 & 226 & 3.7 & 108 & 44.3 & 140 \\
Disagree & 3.4 & 59 & 21.2 & 226 & 0.9 & 108 & 10.7 & 140 \\
Not agree at all & 1.7 & 59 & 0.9 & 226 & 7.4 & 108 & 10.7 & 140 \\
I learned more about nutrition & & & & & & & & \\
through the maternal support group & & & & & & & & \\
Totally agree & 19.6 & 56 & 7.4 & 221 & 37.4 & 107 & 1.3 & 151 \\
$\quad$ Okay & 53.6 & 56 & 61.2 & 221 & 44.9 & 107 & 37.1 & 151 \\
Somewhat agree & 19.6 & 56 & 5.0 & 221 & 8.4 & 107 & 35.7 & 151 \\
Disagree & 7.1 & 56 & 19.5 & 221 & 2.8 & 107 & 10.6 & 151 \\
Not agree at all & 0 & 56 & 3.2 & 221 & 6.5 & 107 & 15.2 & 151 \\
\hline & & & & & & & &
\end{tabular}


Table 2. Evaluation of intensity of intervention on the role of maternal support groups on children's health by health district.

\begin{tabular}{cccccccccc}
\hline & KOLDA & \multicolumn{2}{c}{ MYF } & \multicolumn{2}{c}{ VELINGARA } & \multicolumn{2}{c}{ SEDHIOU } \\
\cline { 2 - 9 } & $\%$ & $\mathrm{~N}$ & $\%$ & $\mathrm{~N}$ & $\%$ & $\mathrm{~N}$ & $\%$ & $\mathrm{~N}$ \\
\hline $\begin{array}{c}\text { I learned more about children's health } \\
\text { through the maternal support group }\end{array}$ & & & & & & & & \\
Totally agree & 14.5 & 55 & 8.6 & 220 & 36.8 & 106 & 2.0 & 148 \\
Okay & 60.0 & 55 & 65.0 & 220 & 47.2 & 106 & 43.2 & 148 \\
Somewhat agree & 18.2 & 55 & 4.1 & 220 & 7.5 & 106 & 31.1 & 148 \\
Disagree & 7.3 & 55 & 18.2 & 220 & 2.8 & 106 & 10.1 & 148 \\
Not agree at all & 0 & 55 & 4.1 & 220 & 5.6 & 106 & 13.5 & 148 \\
I strongly consider the advice given to & & & & & & & & \\
me in maternal support group meetings & & & & & & & & \\
Totally agree & 21.8 & 55 & 5.5 & 221 & 32.0 & 103 & 4.8 & 147 \\
$\quad$ Okay & 55.5 & 55 & 66.7 & 221 & 47.6 & 103 & 33.3 & 147 \\
Somewhat agree & 21.8 & 55 & 4.1 & 221 & 11.6 & 103 & 36.7 & 147 \\
$\quad$ Disagree & 1.8 & 55 & 20.1 & 221 & 2.9 & 103 & 12.9 & 147 \\
Not agree at all & 0 & 55 & 3.6 & 221 & 5.8 & 103 & 12.2 & 147 \\
\hline
\end{tabular}

Table 3. Evaluation of the intensity of the intervention on the attendance of services according to the health districts.

\begin{tabular}{ccccccccc}
\hline & \multicolumn{2}{c}{ KOLDA } & \multicolumn{2}{c}{ MYF } & \multicolumn{2}{c}{ VELINGARA } & \multicolumn{2}{c}{ SEDHIOU } \\
\cline { 2 - 9 } & $\%$ & $\mathbf{N}$ & $\%$ & $\mathbf{N}$ & $\%$ & $\mathbf{N}$ & $\%$ & N \\
\hline $\begin{array}{c}\text { I improved my attendance at } \\
\text { health services through the } \\
\text { maternal support group }\end{array}$ & & & & & & & & \\
Totally agree & 20.4 & 54 & 5.8 & 223 & 39.4 & 104 & 2.7 & 148 \\
$\quad$ Okay & 51.8 & 54 & 65.2 & 223 & 40.4 & 104 & 34.6 & 148 \\
Somewhat agree & 20.4 & 54 & 6.3 & 223 & 12.5 & 104 & 39.9 & 148 \\
$\quad$ Disagree & 7.4 & 54 & 20.6 & 223 & 0.9 & 104 & 10.8 & 148 \\
Not agree at all & 0 & 54 & 4.0 & 223 & 6.7 & 104 & 12.2 & 148 \\
\hline
\end{tabular}

effect of maternal support groups was also carried out. It focused on maternal health, nutrition, child health, advice received and attendance at health facilities. More than $70 \%$ of women surveyed agree that support groups have improved their knowledge of maternal health, nutrition, and children's health. Groups also improved their attendance at health facilities, which is a major asset of the project.

These results are similar to those found in the evaluation of the health box revitalization project by the NGO Africare in the health district of Goudomp where women were more involved through the women's groups in the project interventions [7]. 


\subsection{Health Facility Evaluation}

The institution was found to be $87.9 \%$ clean in Kolda, $83.4 \%$ in MYF, $88.3 \%$ in Vélingara and $95.8 \%$ in Sédhiou. While officers were found to be courteous respectively in the same districts: 91\%, 86.7\%, 89.6\% and 91.6\% (Table 4).

The women surveyed often had confidence in the skills of the health workers (94.8\% in Sédhiou and $88.8 \%$ in MYF). The women recognized the agents' efforts in explaining early initiation to breastfeeding with $76.1 \%$ in Kolda, $75.8 \%$ in MYF, 67.5\% in Vélingara and 68.3\% in Sedhiou (Table 5).

The proportions on the explanation of good cord care ranged from $64.6 \%$ at MYF to $48.1 \%$ at Sedhiou (Table 6).

Explanations of danger signs for mother and baby ranged from 76.9 to MYF to $66.4 \%$ in Velingara (Table 7 ).

The understanding of the health worker's message was $91.1 \%$ in Kolda, $83.7 \%$ in Velingara and Sedhiou. While obtaining FAF was found easier in Sédhiou 93\% and lower in Vélingara with 65.2\% (Table 8).

The usefulness of having a matron as a companion was appreciated. The proportions vary from $93.5 \%$ to Sedhiou and $74.7 \%$ to Kolda. Certainly the accompaniment by a matron reassures. The assessment of free delivery services showed that the women surveyed agreed or strongly agreed with $42.3 \%$ in Sédhiou and $32.4 \%$ in Kolda (Table 9).

Free admission was also appreciated for postnatal care, ranging from $51.6 \%$ in Kolda to $36.5 \%$ in MYF. The lack of privacy is one of the major obstacles to the use of reproductive health services, women surveyed found that it lacked privacy in $28.8 \%$ in Sédhiou $45.5 \%$ in Vélingara (Table 10).

The proportion of women who felt that there was no privacy at the postpartum visit ranged from $44.3 \%$ in Velingara to $28.3 \%$ in Sedhiou. Overall the visit was found to be more satisfactory in Kolda with $91.3 \%$ than in MYF with $85.3 \%$ (Table 11).

Table 4. Evaluation of interventions at the health facility level on the cleanliness and behavior of the agents.

\begin{tabular}{ccccccccc}
\hline & \multicolumn{2}{c}{ KOLDA } & \multicolumn{2}{c}{ MYF } & \multicolumn{2}{c}{ VELINGARA } & \multicolumn{2}{c}{ SEDHIOU } \\
\cline { 2 - 9 } & $\%$ & N & $\%$ & N & $\%$ & N & $\%$ & N \\
\hline The health facility is clean & & & & & & & & \\
$\quad$ Not agree at all & 2.9 & 447 & 3.9 & 429 & 7.8 & 472 & 2.2 & 543 \\
$\quad$ Disagree & 9.2 & 447 & 12.3 & 429 & 11.6 & 472 & 2.3 & 543 \\
$\quad$ Okay & 57.3 & 447 & 66.2 & 429 & 41.9 & 472 & 35.4 & 543 \\
$\quad$ Fully agree & 30.6 & 447 & 17.2 & 429 & 46.4 & 472 & 60.4 & 543 \\
Health workers were & & & & & & & & \\
courteous and respectful & & & & & & & & \\
$\quad$ Not agree at all & 2.2 & 447 & 3.3 & 429 & 4.4 & 472 & 2.7 & 543 \\
$\quad$ Disagree & 6.7 & 447 & 10.0 & 429 & 5.9 & 472 & 5.5 & 543 \\
$\quad$ Okay & 59.0 & 447 & 65.3 & 429 & 41.1 & 472 & 41.0 & 543 \\
Fully agree & 32.0 & 447 & 21.4 & 429 & 48.5 & 472 & 50.6 & 543 \\
\hline
\end{tabular}


A. B. Tall et al.

Table 5. Evaluation of interventions at the health facility level on confidence in the skills and capacities of health workers.

\begin{tabular}{|c|c|c|c|c|c|c|c|c|}
\hline & \multicolumn{2}{|c|}{ KOLDA } & \multicolumn{2}{|c|}{ MYF } & \multicolumn{2}{|c|}{ VELINGARA } & \multicolumn{2}{|c|}{ SEDHIOU } \\
\hline & $\%$ & $\mathbf{N}$ & $\%$ & $\mathbf{N}$ & $\%$ & $\mathbf{N}$ & $\%$ & $\mathbf{N}$ \\
\hline \multicolumn{9}{|c|}{$\begin{array}{l}\text { You trust the skills and abilities of } \\
\text { health workers }\end{array}$} \\
\hline Not agree at all & 1.3 & 447 & 2.3 & 429 & 2.7 & 472 & 1.3 & 543 \\
\hline Disagree & 3.1 & 447 & 8.7 & 429 & 4.9 & 472 & 3.9 & 543 \\
\hline Okay & 65.8 & 447 & 66.9 & 429 & 44.7 & 472 & 45.3 & 543 \\
\hline Fully agree & 29.7 & 447 & 21.9 & 429 & 47.7 & 472 & 49.5 & 543 \\
\hline \multicolumn{9}{|c|}{$\begin{array}{l}\text { Health workers did a good job in } \\
\text { explaining the need for early initiation } \\
\text { to breastfeeding after the baby is born }\end{array}$} \\
\hline Not agree at all & 4.2 & 447 & 6.6 & 429 & 11.0 & 472 & 8.1 & 543 \\
\hline Disagree & 19.7 & 447 & 18.2 & 429 & 22.0 & 472 & 23.6 & 543 \\
\hline Okay & 50.8 & 447 & 66.2 & 429 & 36.0 & 472 & 51.7 & 543 \\
\hline Fully agree & 25.3 & 447 & 9.6 & 429 & 31.5 & 472 & 16.6 & 543 \\
\hline
\end{tabular}

Table 6. Evaluation of interventions at the health facility level on the explanation of good umbilical cord care.

\begin{tabular}{ccccccccc}
\hline & \multicolumn{2}{c}{ KOLDA } & \multicolumn{2}{c}{ MYF } & \multicolumn{2}{c}{ VELINGARA } & \multicolumn{2}{c}{ SEDHIOU } \\
\cline { 2 - 9 } & $\%$ & $\mathbf{N}$ & $\%$ & $\mathrm{~N}$ & $\%$ & $\mathrm{~N}$ & $\%$ & $\mathrm{~N}$ \\
\hline $\begin{array}{c}\text { Health workers did a } \\
\text { good job in explaining the } \\
\text { right care of the cord }\end{array}$ & & & & & & & & \\
$\quad$ Not agree at all & 11.9 & 447 & 7.2 & 429 & 15.8 & 472 & 10.9 & 543 \\
$\quad$ Disagree & 35.3 & 447 & 28.2 & 429 & 26.7 & 472 & 41.1 & 543 \\
$\quad$ Okay & 32.9 & 447 & 56.9 & 429 & 28.6 & 472 & 32.8 & 543 \\
Fully agree & 20.6 & 447 & 7.7 & 429 & 29.2 & 472 & 15.3 & 543 \\
\hline
\end{tabular}

Table 7. Evaluation of the interventions at the level of the health establishments on the explanation of the signs of danger for the mother and the newborn.

\begin{tabular}{|c|c|c|c|c|c|c|c|c|}
\hline & \multicolumn{2}{|c|}{ KOLDA } & \multicolumn{2}{|c|}{ MYF } & \multicolumn{2}{|c|}{ VELINGARA } & \multicolumn{2}{|c|}{ SEDHIOU } \\
\hline & $\%$ & $\mathbf{N}$ & $\%$ & $\mathbf{N}$ & $\%$ & $\mathbf{N}$ & $\%$ & $\mathbf{N}$ \\
\hline \multicolumn{9}{|c|}{$\begin{array}{l}\text { The health worker did a good } \\
\text { job in explaining the danger } \\
\text { signs for the mother and baby } \\
\text { during my post partum visit }\end{array}$} \\
\hline Not agree at all & 7.6 & 447 & 5.4 & 429 & 12.7 & 472 & 12.5 & 543 \\
\hline Disagree & 24.2 & 447 & 17.7 & 429 & 22.9 & 472 & 16.4 & 543 \\
\hline Okay & 48.3 & 447 & 66.2 & 429 & 36.0 & 472 & 48.2 & 543 \\
\hline Fully agree & 19.9 & 447 & 10.7 & 429 & 28.4 & 472 & 22.8 & 543 \\
\hline
\end{tabular}


Table 8. Evaluation of interventions at the health facility level on the understanding of the health worker's explanations and the ease of obtaining iron/folic acid.

\begin{tabular}{ccccccccc}
\hline & \multicolumn{2}{c}{ KOLDA } & \multicolumn{2}{c}{ MYF } & \multicolumn{2}{c}{ VELINGARA } & \multicolumn{2}{c}{ SEDHIOU } \\
\cline { 2 - 9 } & $\%$ & N & $\%$ & N & $\%$ & N & $\%$ & N \\
\hline $\begin{array}{c}\text { You understood what the } \\
\text { health worker told you }\end{array}$ & & & & & & & & \\
$\quad$ Not agree at all & 1.8 & 447 & 3.9 & 429 & 3.6 & 472 & 6.8 & 543 \\
$\quad$ Disagree & 7.2 & 447 & 10.7 & 429 & 12.7 & 472 & 9.4 & 543 \\
$\quad$ Okay & 66.9 & 447 & 73.4 & 429 & 59.1 & 472 & 53.0 & 543 \\
$\quad$ Fully agree & 24.2 & 447 & 11.9 & 429 & 24.6 & 472 & 30.7 & 543 \\
It is easy to get the iron/folic & & & & & & & & \\
acid that health workers & & & & & & & & \\
prescribe at the health facility & & & & & & & & \\
$\quad$ Not agree at all & 6.0 & 447 & 9.8 & 429 & 17.8 & 472 & 2.8 & 543 \\
$\quad$ Disagree & 22.4 & 447 & 18.1 & 429 & 16.9 & 472 & 4.2 & 543 \\
$\quad$ Okay & 44.4 & 447 & 58.9 & 429 & 45.5 & 472 & 47.5 & 543 \\
$\quad$ Fully agree & 22.1 & 447 & 12.8 & 429 & 19.7 & 472 & 45.5 & 543 \\
\hline
\end{tabular}

Table 9. Evaluation of the interventions at the level of the health establishments on the usefulness of the presence of the matron during the delivery and the free of the services related to the childbirth.

\begin{tabular}{|c|c|c|c|c|c|c|c|c|}
\hline & \multicolumn{2}{|c|}{ KOLDA } & \multicolumn{2}{|c|}{ MYF } & \multicolumn{2}{|c|}{ VELINGARA } & \multicolumn{2}{|c|}{ SEDHIOU } \\
\hline & $\%$ & $\mathbf{N}$ & $\%$ & $\mathbf{N}$ & $\%$ & $\mathbf{N}$ & $\%$ & $\mathbf{N}$ \\
\hline \multicolumn{9}{|c|}{$\begin{array}{l}\text { It is helpful to have a matron as a } \\
\text { companion during delivery }\end{array}$} \\
\hline Not agree at all & 8.3 & 447 & 3.7 & 429 & 3.8 & 472 & 2.2 & 543 \\
\hline Disagree & 17.0 & 447 & 12.8 & 429 & 4.0 & 472 & 4.2 & 543 \\
\hline Okay & 56.6 & 447 & 66.7 & 429 & 51.3 & 472 & 61.5 & 543 \\
\hline Fully agree & 18.1 & 447 & 16.8 & 429 & 40.9 & 472 & 32.0 & 543 \\
\hline \multicolumn{9}{|c|}{$\begin{array}{l}\text { All services related to childbirth } \\
\text { are offered free of charge in } \\
\text { health facilities }\end{array}$} \\
\hline Not agree at all & 28.4 & 447 & 29.6 & 429 & 40.5 & 472 & 31.9 & 543 \\
\hline Disagree & 39.1 & 447 & 33.3 & 429 & 22.2 & 472 & 26.1 & 543 \\
\hline Okay & 18.3 & 447 & 23.1 & 429 & 15.2 & 472 & 25.2 & 543 \\
\hline Fully agree & 14.1 & 447 & 14.0 & 429 & 22.0 & 472 & 17.1 & 543 \\
\hline
\end{tabular}

Table 10. Evaluation of health facility interventions on free postnatal care services and intimacy during childbirth.

\begin{tabular}{|c|c|c|c|c|c|c|c|c|}
\hline & \multicolumn{2}{|c|}{ KOLDA } & \multicolumn{2}{|c|}{ MYF } & \multicolumn{2}{|c|}{ VELINGARA } & \multicolumn{2}{|c|}{ SEDHIOU } \\
\hline & $\%$ & $\mathbf{N}$ & $\%$ & $\mathbf{N}$ & $\%$ & $\mathrm{~N}$ & $\%$ & $\mathbf{N}$ \\
\hline $\begin{array}{l}\text { All services related to postnat } \\
\text { care are provided free of } \\
\text { charge in health facilities }\end{array}$ & & & & & & & & \\
\hline
\end{tabular}


Continued

\begin{tabular}{ccccccccc}
\hline Not agree at all & 12.3 & 447 & 30.1 & 429 & 33.5 & 472 & 30.6 & 543 \\
Disagree & 36.0 & 447 & 33.3 & 429 & 23.7 & 472 & 24.7 & 543 \\
Okay & 32.4 & 447 & 22.6 & 429 & 18.6 & 472 & 27.3 & 543 \\
$\begin{array}{c}\text { Fully agree } \\
\text { Nhere was no privacy during } \\
\text { the delivery of the baby }\end{array}$ & 19.2 & 447 & 13.9 & 429 & 24.1 & 472 & 17.5 & 543 \\
$\quad$ Not agree at all & & & & & & & & \\
$\quad$ Disagree & 27.5 & 447 & 26.3 & 429 & 29.9 & 472 & 40.7 & 543 \\
$\quad$ Okay & 35.8 & 447 & 38.5 & 429 & 24.6 & 472 & 30.6 & 543 \\
$\quad$ Fully agree & 22.3 & 447 & 23.8 & 429 & 22.0 & 472 & 15.8 & 543 \\
& 14.1 & 447 & 11.4 & 429 & 23.5 & 472 & 13.0 & 543 \\
\hline
\end{tabular}

Table 11. Evaluation of interventions at the health facility level on the intimacy of the postpartum visit and satisfaction.

\begin{tabular}{ccccccccc}
\hline & \multicolumn{2}{c}{ KOLDA } & \multicolumn{2}{c}{ MYF } & \multicolumn{2}{c}{ VELINGARA } & \multicolumn{2}{c}{ SEDHIOU } \\
\cline { 2 - 8 } & $\%$ & N & $\%$ & N & $\%$ & N & $\%$ & N \\
\hline $\begin{array}{c}\text { There was no privacy during } \\
\text { the postpartum visit }\end{array}$ & & & & & & & & \\
$\quad$ Not agree at all & 28.4 & 447 & 25.6 & 429 & 31.4 & 472 & 41.2 & 543 \\
$\quad \begin{array}{c}\text { Disagree } \\
\text { Okay }\end{array}$ & 38.3 & 447 & 38.9 & 429 & 24.4 & 472 & 30.4 & 543 \\
$\quad \begin{array}{c}\text { Fully agree } \\
\text { Nisit was satisfactory }\end{array}$ & 12.5 & 447 & 11.4 & 429 & 21.8 & 472 & 13.8 & 543 \\
$\quad$ overall & & & & & & & & \\
Not agree at all & 1.3 & 447 & 5.1 & 429 & 1.1 & 472 & 2.6 & 543 \\
$\quad$ Disagree & 7.4 & 447 & 9.6 & 429 & 8.5 & 472 & 8.8 & 543 \\
$\quad$ Okay & 64.2 & 447 & 70.2 & 429 & 44.9 & 472 & 56.2 & 543 \\
$\quad$ Fully agree & 27.1 & 447 & 15.1 & 429 & 46.0 & 472 & 32.4 & 543 \\
\hline
\end{tabular}

Sustainability is understood as the process that allows the continuation of activities and effects related to interventions [8].

The project promoted the involvement of stakeholders at all levels of the health system. A technical committee coordinating and monitoring the implementation of the CBMNHS project has been set up with strong involvement of the DSRSE, which is responsible for implementing maternal and child health policies in Senegal. This can facilitate the appropriation of experiences deemed relevant such as the appropriation of CVAC or even their use for the collection of maternal deaths but also the registration of children for obtaining civil status documents. The project is also relevant if we see the strong involvement of the community, local health authorities and local elected representatives. This is a major asset to the sustainability of interventions.

The project was essentially based on existing resources both at the level of 
structures and at Community level. There has not been a recruitment of qualified personnel and its withdrawal will not result in a loss of human resources. Only community actors benefited from financial motivation. Capacity building of community staff and supervision can be provided by district officials by integrating them with other training and supervision activities at the district level.

To better involve the different layers of the population, the project has set up community organizations specific to each target (women in reproductive age, mother, father, husband, mother-in-law, etc.). Most organizations created at the community level require financial resources that are often obtained from the contributions of the population. This can pose a sustainability problem for these organizations. There is also their specificity to reproductive health as populations face other health problems. The integration of some organizations with mutual health funds, currently the Ministry of Health's flagship strategy to facilitate people's access to health facilities, can be beneficial. This is also the case with AVEC who are likely to be faced with low savings capacity in rural areas. The lack of synergy between these different organizations also hinders their development.

The viability of MAFEs can be problematic due to their low volume of activity. At MYF no women were received in the MAFE. One can also ask questions about the existence of MAFE outside the health structures. However, the integration of the MAFE in the health structure can ensure its sustainability as is the case in Kolda and also in Goudomp in the framework of revitalization of huts [9].

The motivation of community actors is a very interesting strategy. Stopping this financial motivation can have consequences on the performance of these players. However, a reflection must be carried out for the integration of community actors into financial motivation in the context of results-based funding at the level of health structures [10].

\section{Conclusion}

The analysis of the perception of the different actors of the CBMNHS project shows that the project is well conducted in the area of intervention that is the region of Kolda. However, the central question of the success of sustainability is the existence of a withdrawal plan. Indeed, this plan must be studied from the very beginning and must be adapted to the local context. Because it often happens that the organizations disengage completely at the end of the intervention without support. This can jeopardize the sustainability of the strategies because the actors are not well prepared. This situation often occurs when pursuing strategies requires financial or human resources not available to local actors.

\section{Acknowledgements}

We deeply thank the World Bank Group and the African Mother and Child Center of Excellence (CEA-SAMEF) for the ongoing financial and technical 
support to the conduct of this study during these three years in the Kolda and Sedhiou regions. These thanks are also extended to the Micronutrient Initiative Group and the entire community of the two regions.

\section{Conflicts of Interest}

The authors declare no conflicts of interest regarding the publication of this paper.

\section{References}

[1] OMS (2012) Mortalité maternelle. Aide-mémoire. 384.

[2] Agence Nationale de la Statistique et de la Démographie (ANSD) [Sénégal] and ICF International (2012) Enquête Démographique et de Santé à Indicateurs Multiples au Sénégal (EDS-MICS) 2010-2011. 520 p.

[3] Mbonye, A.K. (2001) Risk Factors Associated with Maternal Deaths in Health Units in Uganda. African Journal of Reproductive Health, 5, 47-53. https://doi.org/10.2307/3583322

[4] Yin, R.K. (2003) Case Study Research: Design and Methods. 3rd Edition, Sage, Thousand Oaks, CA.

[5] Ndiaye, S. and Ayad, M. (2006) Enquête Démographique et de Santé au Sénégal 2005. $487 \mathrm{p}$.

[6] Asante, F.A., Chikwama, C., Daniels, A. and Armar-Klemesu, M. (2007) Evaluating the Economic Outcomes of the Policy of Fee Exemption for Maternal Delivery Care in Ghana. Ghana Medical Journal, 41, 110-117.

[7] Tall, A.B., Sow, P.G., Ndiaye, A.A. and Ka, O. (2015) Perception of Beneficiaries and Stakeholders about the Services Offered by Health Huts Put in Place by the Health Project-Community Health of Usaid in the Goudomp Health District (Senegal). Health, 7, 1075-1080. https://doi.org/10.4236/health.2015.79122

[8] Pluye, P., Potvin, L. and Denis, J.L. (2004) Making Public Health Programs Last: Conceptualizing Sustainability. Evaluation and Program Planning, 27, 121-133. https://doi.org/10.1016/j.evalprogplan.2004.01.001

[9] Tall, A.B., Ndiaye, A.A., Ngom, N.F., et al. (2016) Analysis of the Implementation of the Project of Revitalization of Health Huts in the Health District of Goudomp (Senegal). International Journal of Humanities and Social Science Invention, 5, 16-22.

[10] Leighton, C. and Diop, F. (1995) Protecting the Poor in Africa: Impact of Means Testing on Equity in the Health Sector in Burkina Faso, Niger, and Senegal. Health Financing and Sustainability (HFS), Project-ABT Associates Inc., Bethesda, MD, 42. 